\title{
Towards a holistic interpretation of resilient cities' concept: The case of Doha, Qatar
}

\author{
Ali A. Alraouf* (10)
}

\begin{abstract}
Resilience and resilient cities are heavily used terms in the current architecture and planning discourse. Given the mixed interpretations of the concept of "Resilient Cities", this paper calls for a more holistic understanding of the concept and its impact on the way cities are designed, planned and developed. By labelled as resilient, cities should transcend the current limited definition of the resilient cities concept which focuses merely on facing environmental challenges and readiness for climate change impact and other forms of natural disasters. Resilience as an attribute for cities and as will be shown in the case of Doha, the capital city of Qatar, should be holistic and inclusive to embrace all aspects of city development including economical base, cultural assets, social structure and urban development. Using the case of Doha, the paper illustrates a new conceptual understanding of cities' resilience. The paper analyses the contemporary evolution in Doha and highlights the milestones in structuring the new vision for Doha's development as a resilient city holistically. In the last decade, the city was subjected to several radical transformations started from winning the bid to host the 2022 FIFA world cup, decrease in oil prices and finally the sea, air and land blockade imposed on Qatar by its adjacent neighbors. The paper illustrates Doha's model in providing a worthy case of resilience which allows the city to successfully cope with the consequences of all the major shocks, stress and unforeseen challenges, the city have faced in the last decade.
\end{abstract}

Keywords: resilient cities, holistic resilience, Doha, Qatar, urban resilience, Doha sustainable development, climate change, urban impact.

\section{Introduction}

Cities worldwide are challenged by a high complexity of acute and chronic problems, including challenges related to economic development, social polarization and segregation as well as climate change and ecological degradation. Hence, cities must become resilient to a wider range of shocks and stresses. The notions of urban resilience and the resilient city have gained considerable attention and interest over recent years. Urban resilience is a broad concept that is sometimes blurred and abstract. In the scope of this research, we are also interested to relate the concept of urban resilience with the concept of urban sustainability. Our position as explained in the case of Doha, Qatar suggests that the resilience of cities facing variable conditions, threats and forces should also consider the sustainable future of the local communities and the urban territories they 
belong to. As Zhang and Li (2018) indicate that rational urban development can be achieved only when it is both resilient and sustainable. Hence, urban planners, policymakers and researchers should pay equal attention to both urban resilience and urban sustainability before decisionmaking. In current studies, some scholars hold the view that urban resilience has already replaced of urban sustainability as the mainstreaming concept in the discipline of urban studies (Baldwin, 2018; Coaffee, 2017; Meerow, 2016).

The selected case study for the paper, Doha city represents another crucial aspect related to the size of the city and the state and to which extent this would accelerate or hinder the impact of threats, risks and challenges. This paper will explore various aspects of the resilience and its relevance to the design of the built environment in urban areas such as Doha. After familiarization with the concept of resilience and the paper discuss solutions to prepare the neighborhoods, buildings and infrastructures to withstand and recover quickly from unprecedented events.
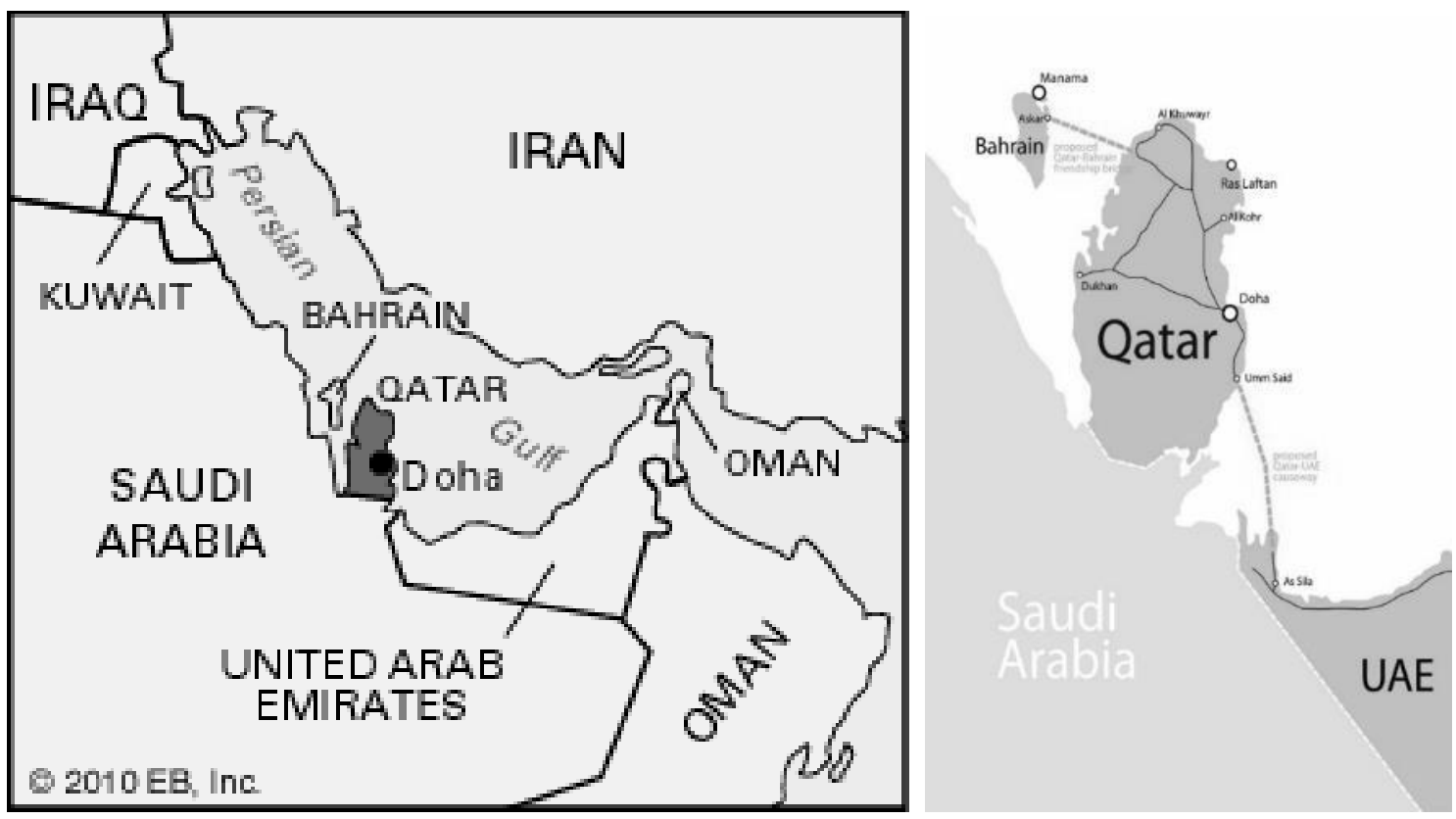

Figure 1 Contextualizing Qatar and Doha within the Geography of the Middle East and the Gulf states (Source: MME Qatar).

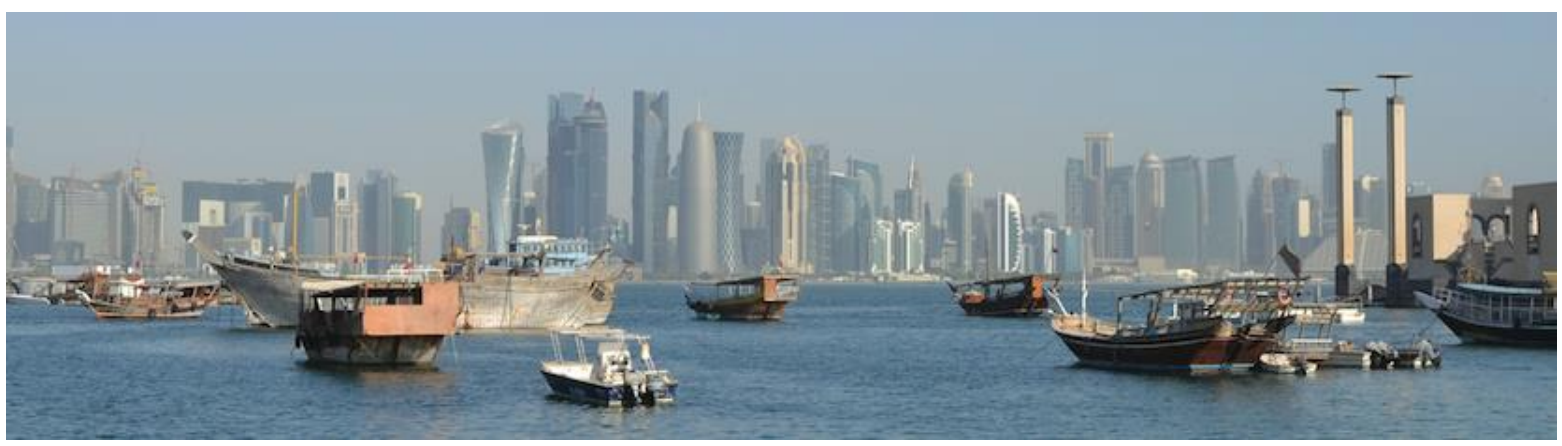

Figure 2 The emerging urbanity of Doha (Source: Author).

2. Interrogating the Standardization of Planning Concepts: The Case of Resilience

In the last decade, resilience is becoming the most recent terminology used in the realm of urban planning and development. Accumulated literature, conferences and journal papers, are discussing 
the topic in the domain of urbanism and planning. Conferences are organized around the globe to discuss how to make cities resilient? Yet, we never pause and question the validity of having a sequence of concepts which would emerge every decade or so to dominate urban planning thinking. Lately, resilience has become an important goal for cities, particularly in the face of climate change. Yet, for a lot of cities around the world, the concept of resilience is still ambiguous. Cities are deeply complex, sophisticated and adaptive systems. The city is the most complex and typical social-ecological system shaped by human beings. Hence, every single city has its own narrative. The mechanistic model of urbanization which is merely using globally accepted concepts coined by international organizations like UN-Habitat should be contested. During the last four decades, UN Habitat, World Bank, International Monetary Fund and other development agencies supported by researchers and academics maintain the ritual of inventing a description for the successful city and change it every five to ten years. Cities in the whole world and particularly in the developing countries were kept confused whenever a new concept emerged; modern, sustainable, smart, green or resilient city. Once a city tries to use its local resources to fully understand the concept and how it will positively affect its development, a new one and even more sophisticated and ambiguous is introduced.

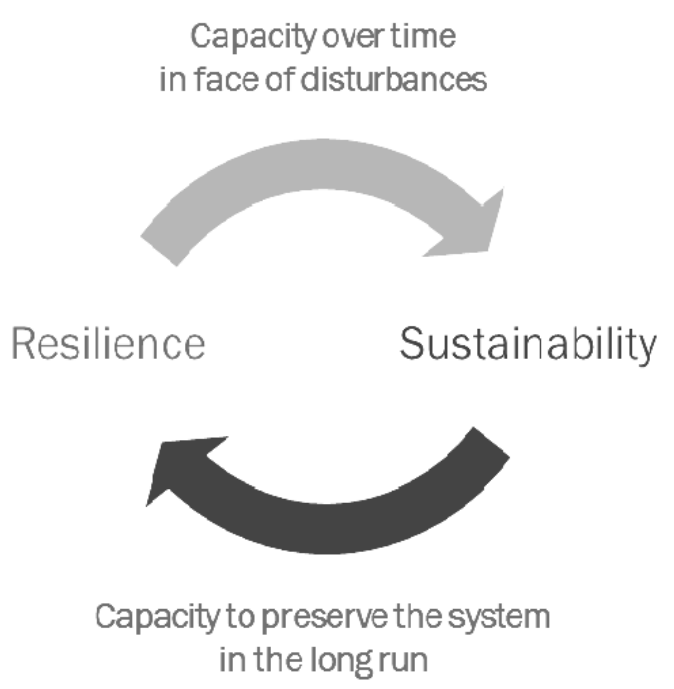

Figure 3 The dynamic relation between resilience and sustainability (Source: Author).

In an increasingly complex and changing world where global problems are felt locally, the approaches used to plan, design, and build our urban neighborhoods are failing due to the adoption of standardized planning concepts. Primarily, the evolution of cities through rigid, top-down action proved ineffective particularly with the continuation of the same problems including environmental threats, urban poverty, housing crisis, car dominance urbanism and other constant challenges. Campbell (2018) argues that the key to fixing our broken patterns of urban development does not lie in grand plans or giant projects; rather, it lies in the collective wisdom and energy of people harnessing the power of many small ideas and actions to make a big difference. He calls this making "Massive Small" change. Such perspective is significant for the discussion of the emerging concept of resilience in cities and urban areas. Hence, a shift towards a holistic understanding of the local context and engaging the local community would pave the way to an authentic and credible urban resilience related to people and places.

To create resilience in urban systems, cities need to be able to learn, adapt and transform across sectors and levels. One definition of urban resilience is the capacity of individuals, communities, institutions, businesses, and systems within a city to survive, adapt, and grow regardless of the kinds of long-lasting pressure and severe shocks they experience. Cities are very vulnerable when any of their subsystems are destroyed or fail to adapt to new challenges. Such a situation may lead 
to a fatal crisis or even destruction. Uncertain factors, such as natural disasters, climate change, energy crises, political instability, financial crises, food security and terrorist attacks play an important role in threatening urban development (Spaans \& Waterhout, 2017). In other words, the concept of resilience should be overextended and transcend the main topic it is associated with; climate change. As explained, cities face plenty of negative and positive challenges which require resilient policies and strategies articulated from within and not imposed by outsiders.

\section{Conceptualizations of Resilience}

Resilience is the ability of a system, community, or society exposed to hazards to resist, absorb, accommodate to, and recover from the effects of a hazard in a timely and efficient manner (Jha and al., 2013). The paper initiates a discussion of how the definition might serve as a boundary object, with the acknowledgement that applying resilience in different contexts requires answering: Resilience for whom and to what? When? Where? And why? Using general terms and global concepts won't help in achieving any level of tangible change as long it is not coupled with a sincere attempt to fully understand the local condition and adopt the concept to the realities on the ground. In the work of great urban theorists such as Jane Jacobs, Christopher Alexander, and E. F. Schumacher, the main invitation for urban planners is to consider locality and value small actions and humble interventions. After reviewing the scholarly literature on urban resilience (Meerow and el., 2016) have concluded that the term has not been well defined. Their justification was based on that existing definitions are inconsistent and underdeveloped with respect to incorporation of crucial concepts found in both resilience theory and urban theory. (Pizzo, 2015) problematizes the introduction of the concept of resilience into the planning domain from three main starting points: 1. The nature of the events which are said to require resilience; 2 . The different nuances in meaning that resilience assumes according to those different events, and 3 . The theoretical and operational problems the concept entails. The paper sustains that multiple sub meanings are embedded within one interpretation of resilience that leave the concept open to rather large margins of ambiguity, which emerge considering its operationalization. The concept seems to fit and to be appropriate within different paradigms, planning traditions and policy frameworks. Its alleged 'neutrality' is one of the main reasons of its pervasiveness, but also of its ambiguity, showing latent controversial implications, which are progressively emerging in critical planning theory.

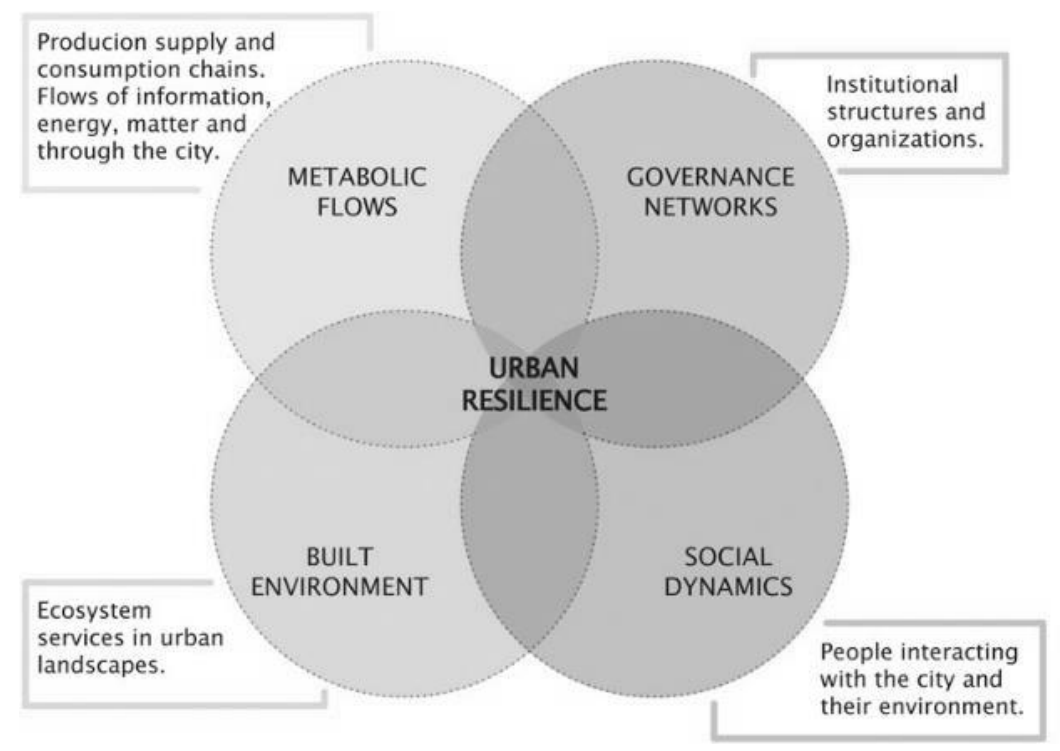

Figure 4 The holistic approach to urban resilience (Source: Author). 


\subsection{Resilience in Urbanism and City Planning}

The holistic understanding of urban resilience resonates with the Sustainable Development Goals (SDG) as compiled by the UN Habitat. Particularly, goal 11 suggests the importance of creating inclusive, resilient, sustainable and safe cities. This paper provides an overview of the development of the resilience concept in the domain of urban development and planning. Over the last two decades the concept of resilience has experienced escalating interest. However, due to a lack of consistency in defining and measuring this theoretical construct within and across disciplines, the recent explosion of literature on resilience has contributed more to confusion than clarity among researchers and policy makers. The notion of resilience is gaining increasing prominence across a diverse set of literatures on cities and climate change. Although there is some disagreement among these different literatures about how to define and measure resilience, there is broad consensus that: (1) cities must become resilient to a wider range of shocks and stresses in order to be prepared for climate change; and (2) efforts to foster climate change resilience must be bundled with efforts to promote urban development and sustainability (Leichenko, 2011). Hence, the paper calls for a need to revisit the concept and its utility to the prosperity of cities. However, resilience has been closely associated with sustainability for more than a decade, although without precise meaning and often as an additional label attached to pre-existing research (Timon, 2014). Urban resilience is a broad concept that is sometimes blurred and abstract. Part of the effort to render the concept to a clearer interpretation is first to assert that Urban resilience addresses adaptation as well as mitigation. It is associated with spatial planning policymaking in the context of different levels and forms of uncertainties. Therefore, urban resilience provides a new way of framing and responding to uncertainty and vulnerability. Considering this interpretation, urban resilience offers an alternative paradigm for planning strategies.

\section{Contextualizing Doha: The Rising Competition between Gulf Cities}

Before discussing the experience of Qatar, this section is contextualizing the State within the Gulf context and elaborates on the notion of the regional competition as a form of stress and challenge. While most people think of cities developing organically over hundreds of years, many who live in the Gulf are aware of how quickly some cities can grow, expanding exponentially in terms of buildings, infrastructure, and population. Much of the rapid transformation has been guided by an intense inter-city competition to attract investments, human resources and tourism particularly because of oil prices decline. The Gulf States have grown rapidly due to their large reserves of oil and gas. Being aware of ending resources, the era after the oil is already being planned by the governments in the Gulf region (Höselbarth, 2010). The Gulf States while mostly young and small, they are the largest builders and developers in the world. Every single capital Gulf city is characterized with shopping malls, skyscrapers, artificial islands, gigantic airports, real-estate fantasies and signature museums. Yet, they have also realized that another transformation is needed from oil-based to post-oil societies. With oil resources running out, a focus on the post-oil era is a priority.

The first wave of competition was manifested in using the lucrative oil revenues in constructing a distinct image of modernity and approaching the global paradigm. Dubai was the initiator of this wave with the deliberate focus on iconic developments resulting in a model which was blindly adopted in other Gulf and Middle Eastern cities. The second wave of Gulf cities' competition emerged from the realization of the depletion of carbon resources or the gradual loss in its global value due to advances in renewable energy sources. A fact which was substantiated by the sever decline in oil prices which construct the backbone of Gulf States' economic base. As these cities compete, aiming to highlight their unique offerings and attempting to clearly distinguish themselves from other cities, they have chosen to rely on place-branding as a tool. The staging of events of international importance (such as Formula One Races in Bahrain and Abu Dhabi, upcoming World Expo 2020 at Dubai and prospective 2022 FIFA World Cup at Qatar), the emphasis 
awarded to star-architecture and the emergence of strongly themed mega-projects characterize such development. Thus city-positioning and place-branding begin to assume the status of urban development models (Mishra, 2016). All Gulf cities are in the process of diversifying their economic base, with the vision of transitioning to a sustainable post-oil future, they are positioning themselves as places to visit, work and live. Place-branding has emerged as a significant trend across the Gulf cities in the construction of this image and consequently in the production of places.

Questions about the future of contemporary Gulf cities are important as the drastic changes taking place particularly in the economic side, indicates a necessity to consider a new blueprint for Gulf cities' future. Replacing glittering facades, high-end hotels, artificial islands, huge shopping malls, and the tallest constructions of the world, the region nowadays need to attract people from all over the world to contribute to a different kind of economy. The catalyst for the old model of development was the discovery of huge amounts of oil and gas resources in the 1960's leading to prosperity (Gremm and els., 2015). But oil reserves will be exhausted soon. How do the cities of the Gulf region respond to this drastic change? Are they, like so many other cities in the world, trying to reach the status of a knowledge or creative city? Is it indeed a target of these wealthy oil-based cities to set up a knowledge society based on knowledge economy not mere natural resources?

\section{The Narrative of Qatar: A Small State with Big and Legitimate Aspirations}

The skeptical positon regarding Qatar's ability to construct an inspiring model of development is based on its small size, limited population and the massive presence of expatriates. Roberts (2015) stresses the concept of "brand Qatar" as a catalyst which helped the small size State to gain global recognition and changed its character so completely in so short a period. He based his interpretation on shifting the leadership in 1995 to an emerging leader with a progressive vision for the future. The State of Qatari's cultural identity, which was formed throughout the history, represents a balanced combination between conservatism and liberalism. The pillars of this progressive vision are diversified and balanced foreign relations, establishing a leading role in media through Al Jazeera network, and extensive investment in gas production and liquefaction. Ultimately, bold initiatives require bold leadership and Qatar is yet again, blessed with this resource (Richer, 2014). Additionally, Kamrava (2013) argues, Qatar's enormous oil and gas wealth has permitted the ruling Al Thani family to exert a disproportionately large influence on regional and even international politics. Qatar is, as Kamrava (2013) explains is a "tiny giant": although severely lacking in most measures of State power, it is highly influential in diplomatic, cultural, and economic spheres. Kamrava presents Qatar as an experimental country, building a new society while employing what he calls "subtle power." It is both the headquarters of the global media network AI Jazeera and the site of the U.S. Central Command's Forward Headquarters and the Combined Air Operations Center. Qatar's effective use of its subtle power, Kamrava argues, challenges how we understand the role of small states in the global system.

The fact that Qatar is a small State amplifies the need for a more comprehensive understanding of the elements of this small state's strength which led to its ability to convert a crisis targeting its leadership and sovereignty to a case of a positive and smart resilience and resistance. As (Abdelmoula and Taguia, 2018) argue, Qatar smartly used the notion of soft power as one of the elements of Qatar's strength and resilience in the face of the blockade. One of the major miscalculations of the blockading countries is that they consider Qatar as a weak rival due to its small geographical size and limited population. They failed to acknowledge the previously emerged tier of States and cities where size doesn't matter as other forms of influence are considered including soft power and subtle diplomacy. Hence, the effective and influential small is by far better the useless big. 

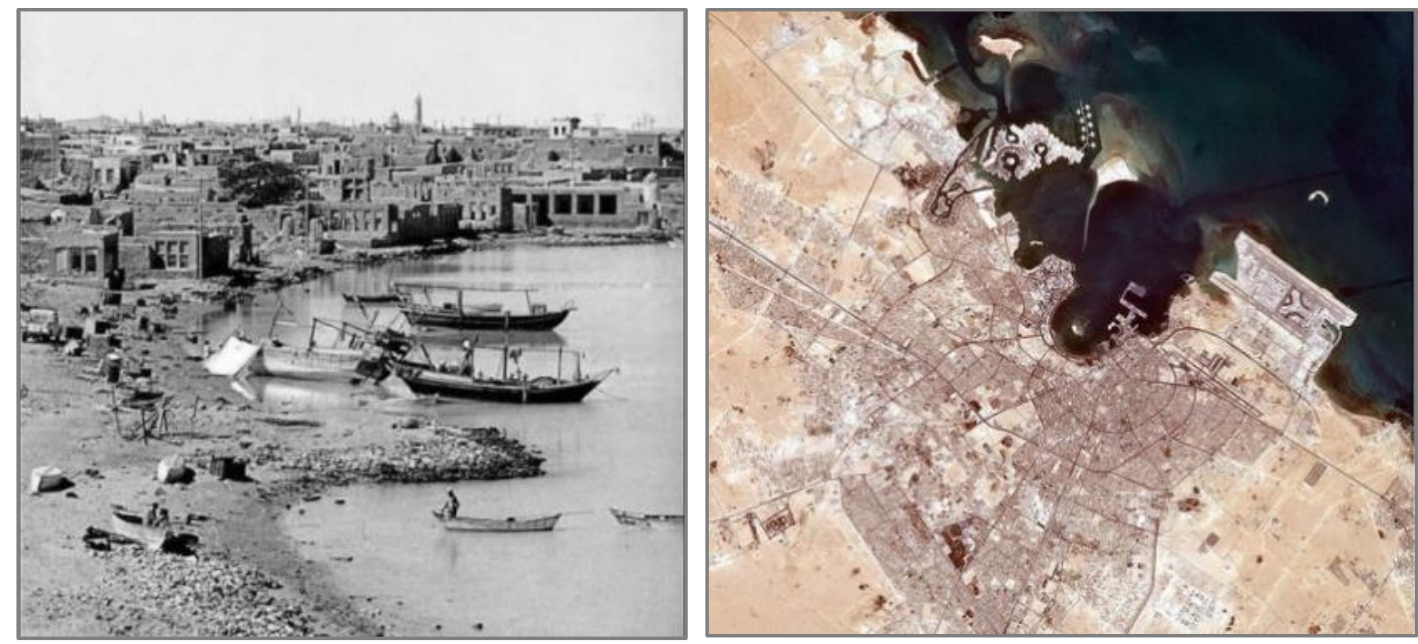

Figure 5 and 6: Doha's Evolution from a humble traditional settlement (1940s) to a metropolitan urbanity (2021) (Source: Courtesy of Ministry of Municipality).

Qatar has invested heavily in soft power during the past two decades. In this regard, Qatar operates on seven integrated fronts forming a strategic shield by which attacking it would seem difficult without the whole world noticing. These fronts are: diplomacy, media, economy, humanitarian efforts, culture, sports and tourism. As Nasser Al Tamimi argues that by targeting these components, the blockade axis has failed (In Abdelmoula and Taguia, 2018). The influence of art and culture can be seen as an engine to promote the resilience of regional and urban economies (Cooke and Lazzeretti, 2018). The contribution of some creative regions and cities as places in which processes of transformation, innovation and growth are activated in response to external pressures. Hence, cultural and creative resources may offer a sustainable model which was followed by Qatar by investing heavily in such domains.

\section{Contesting Doha's Model of Resilience}

In this section, an analysis of the most dominant forces that challenged the development of Doha city in the last decade will be provided. Hence, all the strategies, processes and policies which were adopted by the city will be shared to illustrate the city's resilience model. Interestingly, some of these dominant forces were celebrated like winning the bid to host the 2022 FIFA World Cup, while other were a substantial shock and have created a seismic impact on the city's people, economy and development. Doha was alert for the critical need for a flexible and dynamic approach to building resilience that goes beyond risk mitigation. Therefore, in the coming sections, three main challenges will be narrated and Doha's answer to each of them will be illustrated. Three milestones which are representing the most alarming challenges that Doha have faced in the last decade, analyzed in a chronological order. The analysis provided illustrates the wider interpretation of the challenges which require a resilient plan. The notion of a city challenge is also extended as it does not all the time implies negativity. Cities need resilience also to deal with positive challenges facing its development and progress. Therefore, the milestones analyzed go all the way from economical threats, hosting a global event to a comprehensive blockade.

\subsection{Challenge One: March 2008; the Inevitability of the Post-Oil Paradigm}

A major challenge which the paper addresses is the fluctuation of oil prices and how Doha is structuring a vison for the city in the post-carbon paradigm. Such a paradigm implies a move from oil-based economy to a knowledge-based economy and how to plan the city to facilitate such a new economical paradigm. With an unprecedented financial resources, creative strategic thinking and political commitment, Qatar is constructing a new development and urban brand; Dohaization 
which is a brand but also a continuous dynamic process1. The case of Doha is stimulating as new mega projects are made to pave the way for a new development vison structured upon the value of knowledge economy and knowledge-based urbanity. By any measure, Qatar's growth is phenomenal; in the past decade, the population has trebled, and the size of metropolitan Doha has increased fourfold. From its humble origins as fishing and pearling village, Doha has emerged as an expanding world city, where ambition and means are fueling exciting experiments in education, health, sports and culture (Framherz, 2012; Jodido, 2014; Alraouf, 2016).
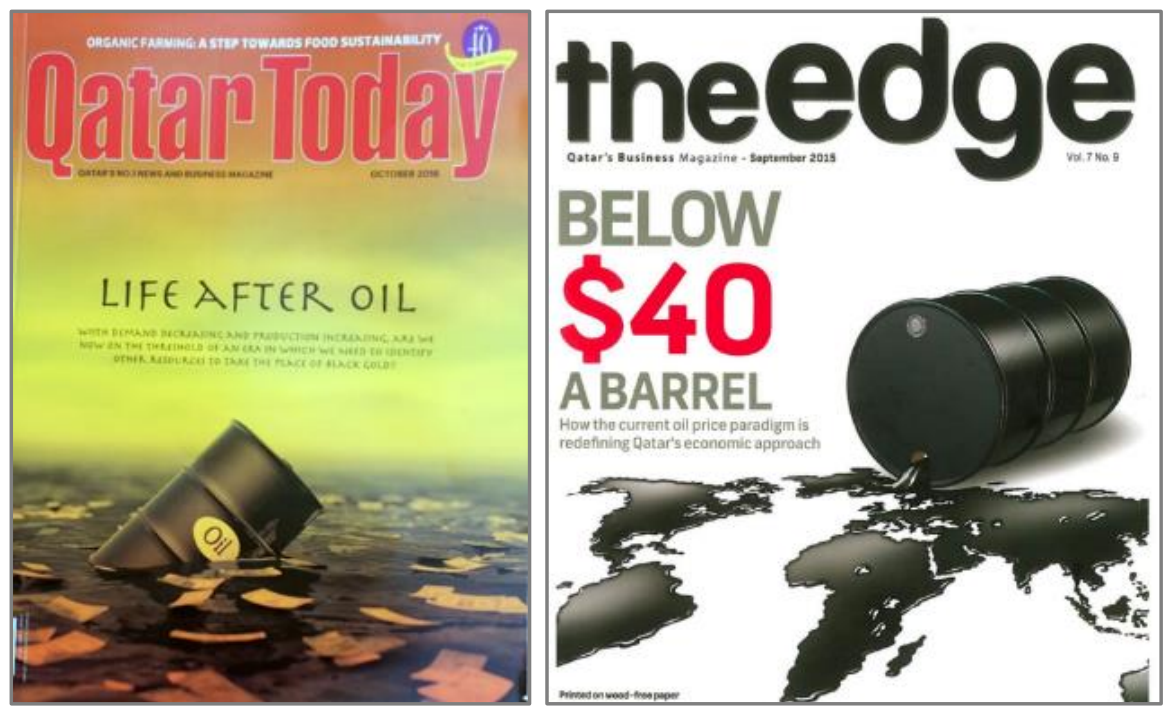

Figure 7 Facing the decrease of oil prices is one of the significant challenges facing Qatar as oil and gas revenues are still the backbone of its economy (Source: Author)

For a better understanding of how Doha came to structure its current identity, an investigation into the State's main strategy and the articulation of Qatar's role regionally and internationally is crucial. In this section, we will discuss the State's main strategies which affected the development of Doha. The Paper sheds light on the concept of Doha's attempt to construct a new identity which transcends the model that was created by Dubai's iconic development and real-estate fantasies. Then, the notion of knowledge economy as adopted by the State and clearly articulated in QNV 2030 will be analyzed to illustrate the quantitative and qualitative shift towards knowledge-based urban development in Doha. Evidently, in the last decade a new pattern of planning interventions can be clearly observed in the urban fabric of Doha. These new interventions described as the city's mega projects due to its size, location, population served and visual and urban impact.

\footnotetext{
${ }^{1}$ The term Dohaization was coined and used for the first time in Gulf Research Meeting at Cambridge and later published in Alraouf, Ali. 2016. “Dohaization": An Emerging Interface between Knowledge, Creativity, and Gulf Urbanity. pp.: 47-68. In Katodrytis, G. and Syed, S. Gulf Cities as Interfaces. Cambridge: Gulf Research Centre Cambridge.
} 

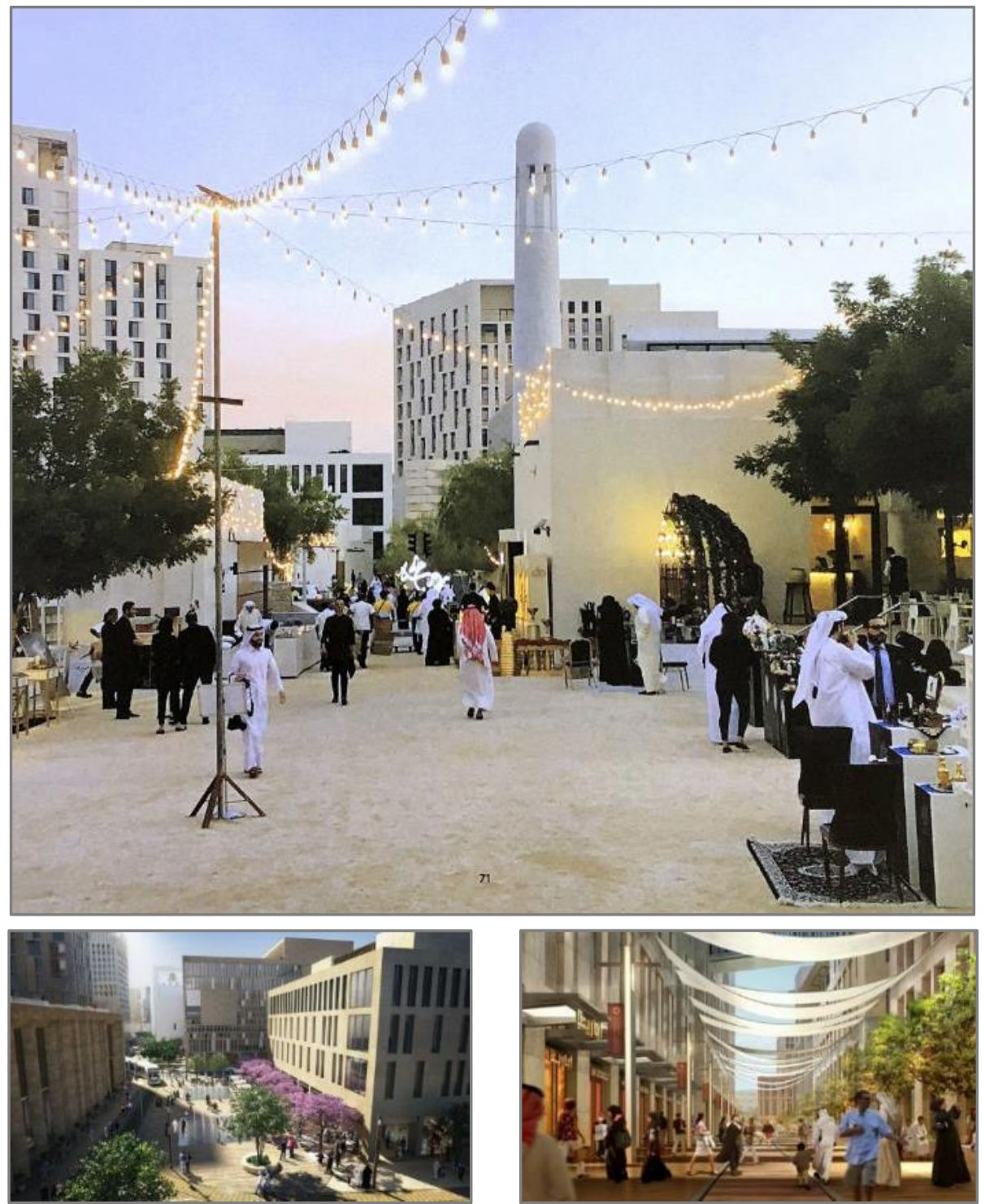

Figure 8 and 9 The post-oil urbanism suggests a paradigm shift towards walkability and the significance of vibrant public spaces, the Case of Doha City Center (Source: Author).

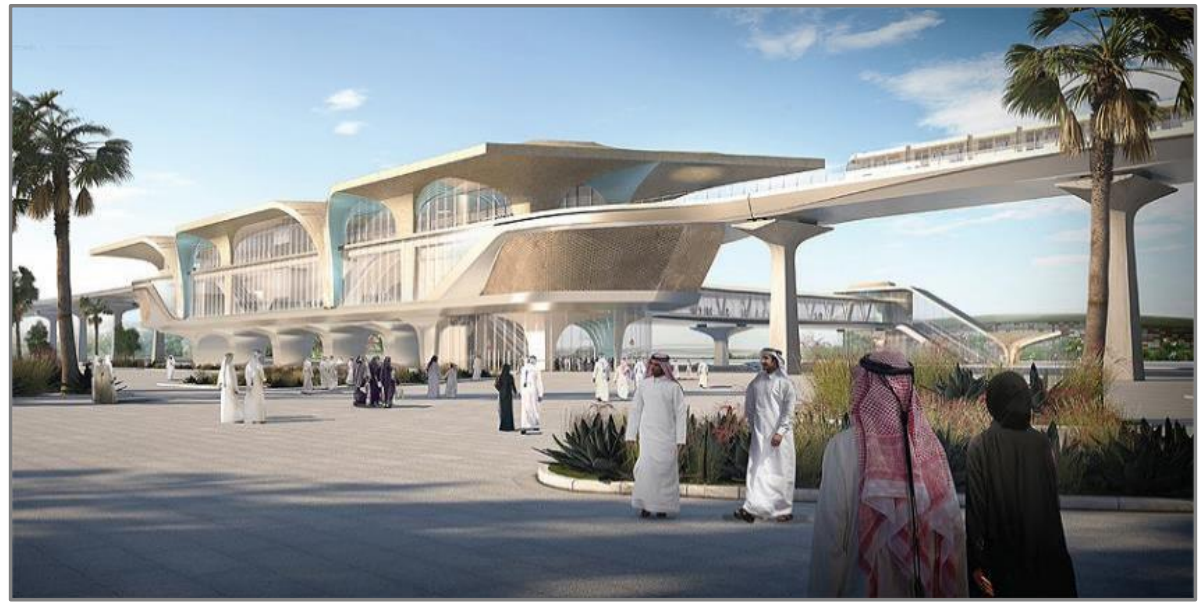

Figure $10 \mathrm{~A}$ tranisti oriented developmt strategy was adopted in Doha to mitigate the impact of post carbon era's development. 
Doha is considered by many indicators as the most advanced city within the Middle East to adopt knowledge economy as a conceptual base for its 2030 vision. Qatar did a radical transformation to go beyond the typical image of a Gulf city relaying on presumably endless assets of oil and gas. A move towards being a regional center for education, knowledge and culture is the new aspired sense of identity for the Gulf State. A major investment in knowledge-based urban development characterizes major projects in the country during the last five years (Alraouf, 2008; 2014). This new identity of Qatar paved the way for a new paradigm in Doha's urbanity which can be best described as the Knowledge-based urban Development Paradigm. Qatar has become a showplace for renowned architects, several U.S. universities have established campuses there, and it will host the FIFA World Cup in 2022. The quantity and the quality of architectural and urban projects which will be added to the city's urbanity to facilitate hosting the 2022 FIFA World Cup would definitely make Doha a very unique world destination. Significantly, Doha has gained global significance through the growth of knowledge economy related projects. The city's new urban development and its spatial qualities contribute to the global attractiveness of Doha for knowledge economy investments, firms and people. Such urbanism fulfills the requirements of Knowledge workers coming to the city from literally every spot of the globe anticipating an attractive smooth quality of life which would foster their creativity and innovation.
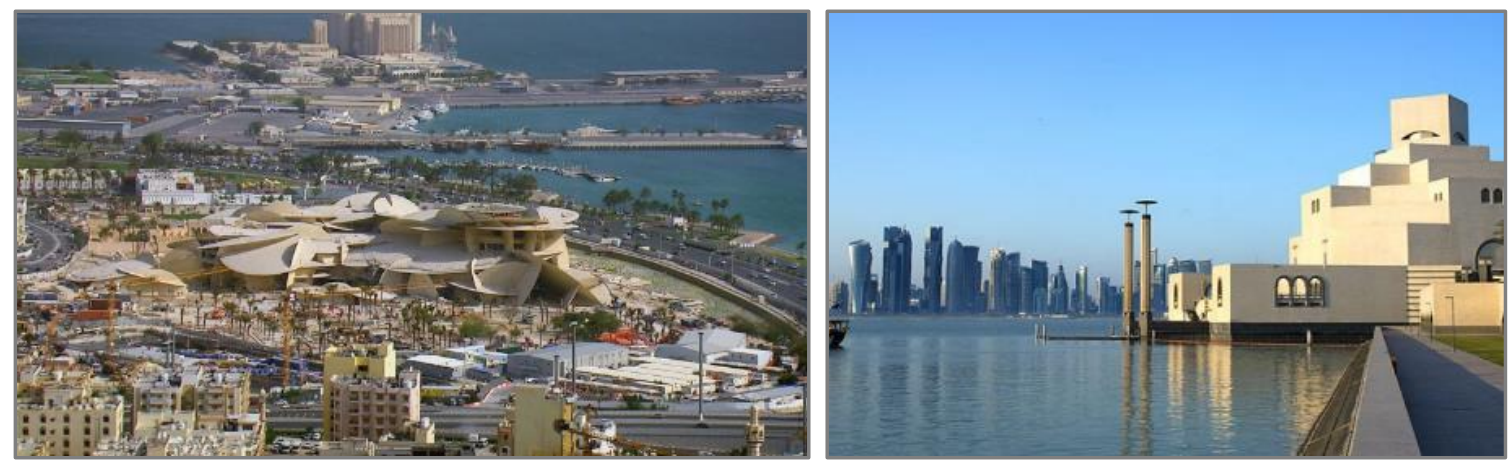

Figure 11 and 12 The new cultural districts help Doha in establishing a new form of Knowledge-based Urban Development (KBUD).

With increasing awareness about the carbon emissions and the negative impacts of climate change, the paper evaluates Doha's attempt to transform its urban movement pattern from purely car-dependent city to a model for a transit-oriented development with the vitalization of connected network of public transportation, pedestrian streets and bicycle routs. Doha's model of urban resilience as reflected in the city's masterplan is answering the fundamental question of how to design and operate the city so it can withstand major threats and how to recover from them? Yamagata and Maruyama (2016) argue that land-use planning and carbon-neutral scenarios for urban planning are fundamental tools in urban management leading to a better urban resilience.

As a conclusion, Doha's readiness for the post-oil paradigm can be perceived on three levels: strategically, urban planning and architecture. As explained in the earlier section, Doha is moving strategically towards a development vison articulated around the concept of the inevitable move towards knowledge and creative economy. On an urban planning level, Doha is moving towards a compacted model of urbanism by relaying on multicenter-city development to stop the unsustainable sprawl which was the dominating pattern in the last three decades. In addition, the city is activating a solid transit-oriented development approach to consider public transportation as the main mode of transportation within the city. Finally, on the architectural level, both Qatar Green Building Council (QGBC) and Gulf Organization for Research and Development (GORD) were established to produce, develop and monitor the implementation of green and sustainable architecture principles in the new buildings designed and built in Doha and all Qatari cities. 


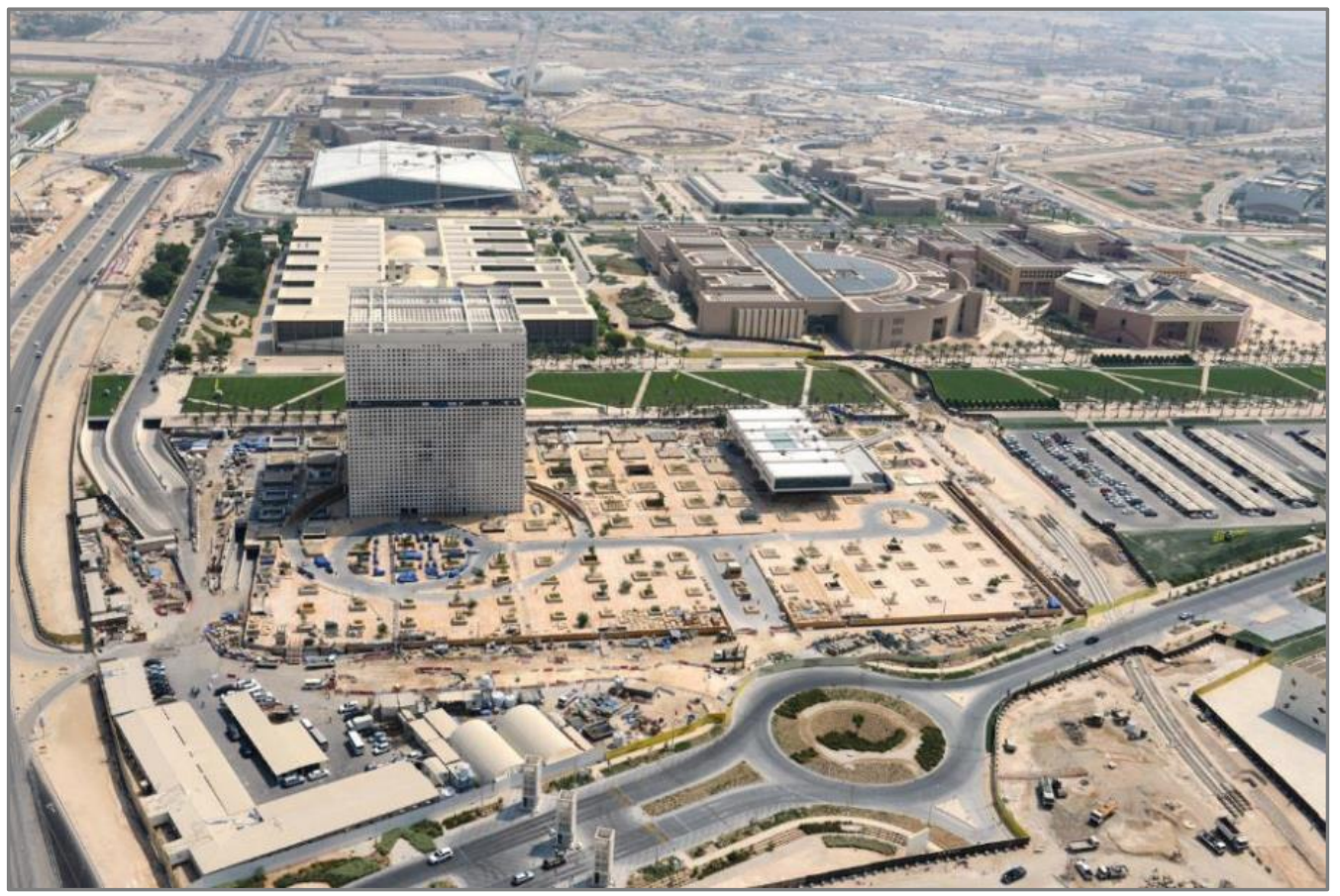

Figure 13 Education City as a manifestation of Doha' strategic vision to move towards being a creative and knowledge city. A city dedicated to establishing a culture of education, research, creativity, and innovation (Source: Author).

\subsection{Challenge Two: October 2010; Winning the Bid for Hosting FIFA 2022}

Qatar's interest to brand itself as an appropriate choice to host mega sports events started with preparing Doha to be the sports capital in the Middle East. A fact which was successfully demonstrated when the country organized the 2006 Asian games and gained the world respect. Doha was the first city in its region and only the second in West Asia (following Tehran in 1974) to host the games. Later, Qatar has lost its bid for the 2016 Olympics, but has vowed to try again. On the second of December 2010, Qatar was selected as the host country for the 2022 FIFA World Cup. The model of Qatar hosting a major global world event generates number of interesting issues. Some crucial questions emerge; how the city/State was able to win the bid? How the city/State is using the event to brand Qatar, Gulf and the Middle East? How the city/State is moving beyond hosting the event to creating a continues legacy which will positively and sustainably contribute to the prosperity of the State. All the lessons learned from analyzing the different world experiences in hosting major global sports inspired Qatar to take a different route. One can observe the transformation in strategic thinking towards the whole process of hosting the FIFA event in Qatar. When Qatar was declared as the host country for the 2022 FIFA World Cup, an immediate decision to form an organizing committee with outstanding authorities and capabilities was issued. The committee was called 2022 FIFA World Cup Supreme Committee and it has an excellent team of consultants, advisors, strategic thinkers, logistics experts and some members from the team who prepared the successful file that won the bid. Later and considering the new understanding that hosting the event is a catalyst for future progress and community development, the whole conceptual approach has changed. Also, the title and the responsibilities of the committee have altered. The new title for the 2022 FIFA World Cup organizing body in Qatar is Supreme Committee for Delivery and Legacy (SCDL). The model as discussed in the outcomes of the supreme committee has learned profoundly from recent experiences in hosting the FIFA cup particularly in Brazil and South Africa. The main responsibilities of the committee are being confident that Qatar will provide a state of the art experience in hosting the event but more significantly that the event will positively 
affect the future prosperity of the country and create a sustainable legacy that would last for generations to come.

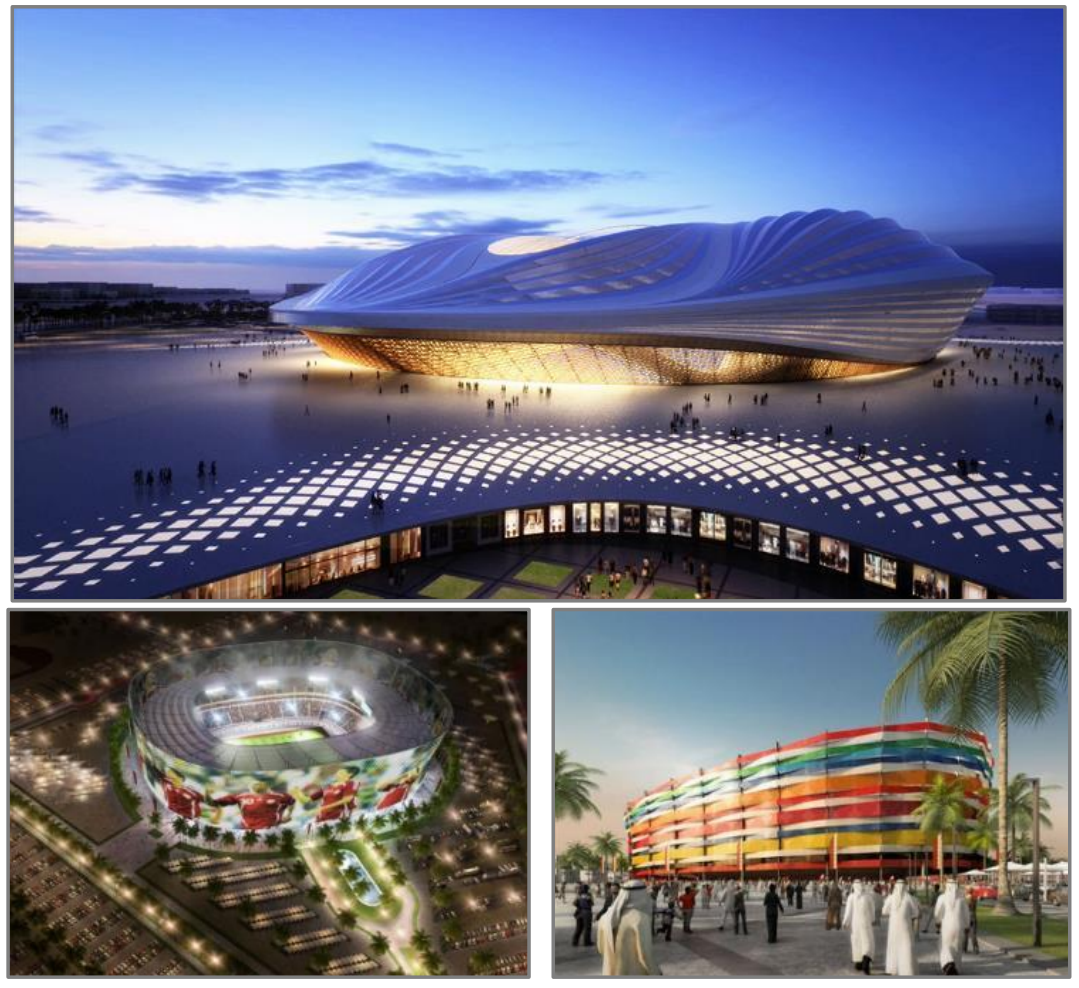

Figure 14 Doha is balancing hosting the 2022 FIFA World Cup with the future aspirations of the city.

Qatar is consciously aware of the day after oil and is using the unprecedented opportunity of hosting the 2022 FIFA world cup as an engine to inspire a new blueprint for the future of its people and cities (Nadine, 2014). The strategic thinking transformation towards how to host a global sports event in Qatar resulted in a new blueprint and a road map. This blueprint was based on several integrated aspects. All of which were designed and assembled in a way to guarantee that the process of hosting the event will be successful not only during the thirty days of the competitions but for decades to come. Qatar has been using sports strategically as a foreign policy tool that contributes to national security and allows the country to gain soft power. Even on the level of enhancing the global image after the blockade, Qatar smartly used sports to deliver a positive message about its stability and commitment to global investment. Current evidence particularly during the events of the 2018 FIFA world cup in Russia and the excellent presence of Qatar suggests that The 2022 World Cup in Qatar will happen, although not everybody might like that. As explained earlier, hosting the Cup will be a turning point for Qatar and would substantiate its global reputation but it is not the goal. The goal as explained in the paper is to use hosting the event as a catalyst for a better post 2022 Qatar. Hence, the development associated with hosting the 2022 World Cup in Qatar is for people and future not only for a time restricted event.

\subsection{Challenge Three: June 2017; A City under Siege: A Plight or a Historical Opportunity}

The paper reveals the exclusiveness of Qatar's experience in management of the crisis and resistance of the blockade in terms of the strategies used to overcome the impact on its urban development and social integration. The other significant aspects like economy, politics and security were investigated in other research projects primarily (Abdelmoula and Taguia, 2018; 2017) and (Roberts, 2017). Qatar's confrontation of the land, sea and air blockade imposed on it by Saudi Arabia, the United Arab Emirates (UAE), Bahrain and Egypt on 5 June 2017 forms the third and most threatening major challenge that the small State faced in its modern history. On June 5, 2017, Saudi Arabia, the UAE, Egypt and Bahrain announced the implementation of an air, sea and 
land blockade of Qatar. This came after they accused the government of supporting terrorism in the region, a claim that Qatar has refuted. One of the major forces which led to unprecedented challenge for Doha and Qatar is the blockade imposed by its close neighbors. The blockade as the paper illustrates opened new dimensions in the city's acknowledgment and comprehension of resilience. Ironically and surprisingly, in the 50th anniversary of the six days war in 1967 where Arab armies were humiliated and defeated, four Arab States decided to activate an unprecedented sea, air and land blockade against Qatar2. The whole Middle East and the world wake up on the fifth of June 2017 reading the news about the decisions imposed by Saudi Arabia, United Arab of Emirates, Bahrain and Egypt on their neighbor and founding member of the Gulf Cooperation Council (GCC), Qatar. Pressure mounted further after relations with its regional neighbors hit rock bottom last June. Since then, Saudi Arabia has led a boycott of Qatar, with full participation from Bahrain, the UAE and Egypt. Planes have been prohibited from flying to Doha, banks from dealing with Qatari banks, and the country's influential satellite TV channel, Al-Jazeera, remains off the airwaves throughout most of the Arab World. Given that prior to the blockade some $60 \%$ of Qatari trade moved through either Saudi Arabia or the UAE, officials at once began implementing measures to protect the economy from disruption

The blockading countries tried to use the Gulf Cooperation Council (GCC) as a tool to suffocate Qatar and isolate it both from the Gulf and the Arab world. Qatar conducted a swift and effective diplomatic campaign in the main regions in west and the east. At the Gulf level, the neutrality of both Kuwait and Oman provided leverage for Qatar, albeit without direct support. As (Abdelmoula and Taguia, 2018) illustrate, Qatari efforts that succeeded in positively neutralising the positions of these two countries were based on four levels of power: the media, moral power, diplomacy, and investment prospects. The effective diplomatic campaign also resulted in an interesting change in the USA's position. As Patrick Theros (in Abdelmoula and Taguia, 2018) argues despite Qatar's delay in the competition for Washington's heart and mind, Doha succeeded in record time to win American institutions over and change the position of the US administration, as well as President Donald Trump himself, who appeared to be in favour of the blockading countries at the outset of the crisis. The rebuilding of Qatari- US relations was launched on a stronger basis than in the past and Qatari efforts led to the holding of the strategic dialogue sessions in 2018. Qatar responded by implementing a series of reforms, seeking out new trade partners and amplifying economic diversification efforts. The blockade has also fuelled greater self-sufficiency in sectors such as agriculture. Since 2017 Qatar has imported thousands of cows and chickens, rapidly expanding domestic agricultural capacity. The country now produces all of its own dairy and fresh poultry, whereas in 2017 domestic production of each stood at only 20\% and 10\%, respectively. In 2019 the country even began exporting milk to Afghanistan, Oman and Yemen.

\subsubsection{The Social Cohesion as a Catalyst for City Resilience}

Baldwin and King (2018) emphasize that strong social networks and social cohesion can be more important for a community's resilience than the actual physical structures of a city. That what was exactly noticed in Doha after the activation of the blockade. More significantly, urban planning and design support these critical collective social strengths by stressing the necessity of creative spaces for all and enhance the inclusivity of the city's urbanity. In the process of realizing the goal of both sustainable and resilient development, we should see the dominant role of social factors such as urban governance in the process of urban adjustment and adaptation. The social aspect will be also addressed in the paper as Doha, like most of Gulf cities, has a much-diversified population coming from all corners of the world.

\footnotetext{
${ }^{2}$ The claimed justifications of the crisis were based on fabricated statements attributed to the Emir of Qatar posted on Qatar News Agency's website by hackers supported by the UAE.
} 


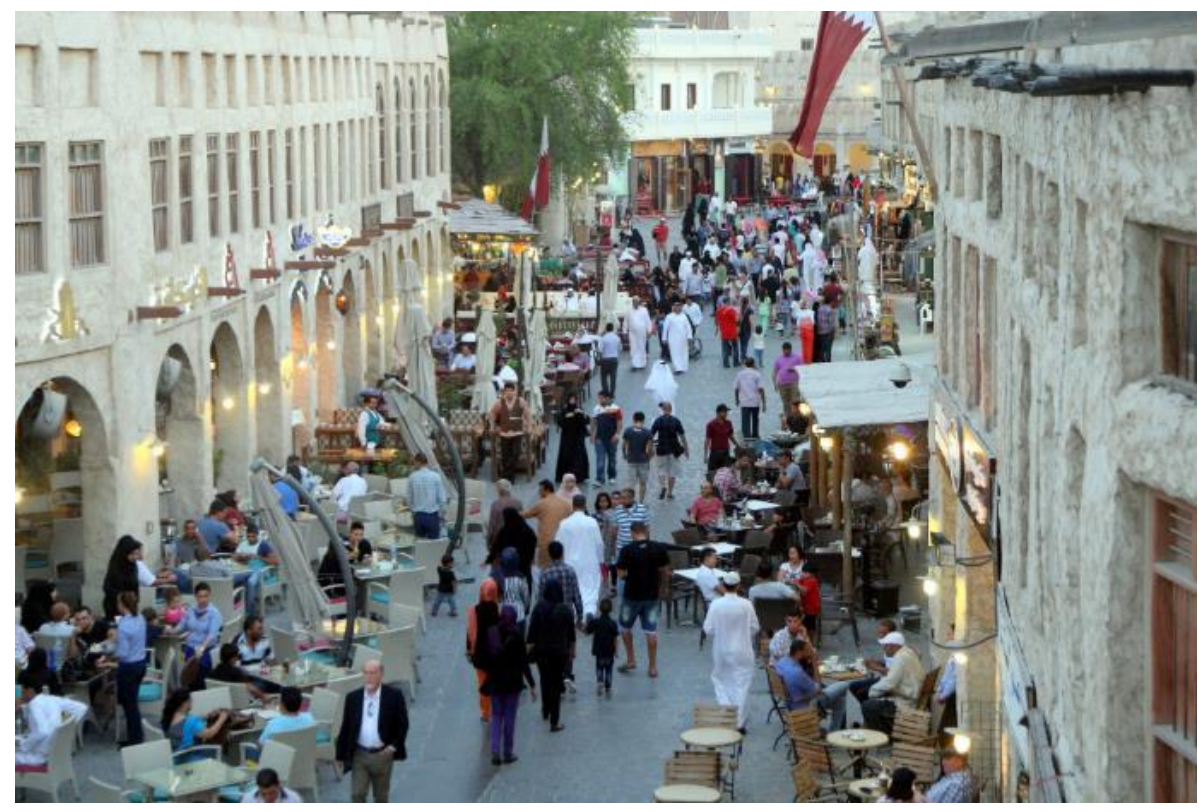

Page | 152

Figure 15 The city spaces are planned to accommodate the different social groups and emphasize the social cohesion (Source: Author).

The city is taking several measures to create better connections between expatriates and the city significantly sense of belonging and ownership which would radically help in inspiring the city's overall population of locals and expatriated to better defend the city and take a solidifying position towards realizing its future aspirations. The paper concludes with articulating a more holistic framework for city resilience which takes into consideration the multifaceted nature of the city and better prepare it for different forms of changes and transformations which might occur in the future. Coaffee and Lee (2017) examine how the concepts and principles of resilience exert increasing significant influence over the form and function of planning. Their discussion of the 'politics of resilience' in which fundamental questions of social and spatial justice are posed is relevant to the notion of social cohesion in Doha after activating the blockade.

\section{The Role of Unique Infrastructure (Ports and Airports)}

An immediate effect of the blockade was the re-orientation of Qatar's trade away from its Gulf neighbors. Data from the Ministry of Development Planning and Statistics showed imports to Qatar fell by some $40 \%$ immediately after the announcement of the blockade, as the sanctions cut off the country's main trade routes. Iran and Turkey offered assistance by delivering various consumer products by ship and plane, while Iran also opened its airspace to commercial flights headed to Qatar, offsetting the closure of connections with the blockading countries. The trend has continued over the past two years, with Qatar shifting its trade relationships towards new partners. To facilitate such new trends and enhance the pace of new connections, the city must be prepared with unique urban infrastructure particularly in the domain of external and internal transportation. The investment in smart infrastructure particularly in the field of urban transportation and applying the concepts of transportation hubs in envisioning the roles of Qatar port and airport, allowed Qatar to quickly overcome the impact of the blockade. As Nasser Al Tamimi (Abdelmoula and Taguia, 2018) discusses the importance of having completed the expansion of Hamad Port six months ahead of the set plan as an economic leverage for Qatar and as an important tool in facing the blockade through the provision of direct international shipping lines. This sea port is one of the largest in the Gulf region and the Middle East and has been able, in record time, to free Qatar from its previous reliance on the port of Jebel Ali in Dubai and land lines with Saudi Arabia. Complementing these measures is the launch of Qatar's inaugural special economic zones (SEZs). Both the 34-sq-km Um Al Houl SEZ, located next to Hamad Port, and the 4-sq-km Ras Bufontas site, next to Hamad International Airport in Doha. The first will focus on maritime industries, 
petrochemicals, building materials and logistics, while the second is expected to feature investment opportunities for companies operating in aerospace and advanced technologies.
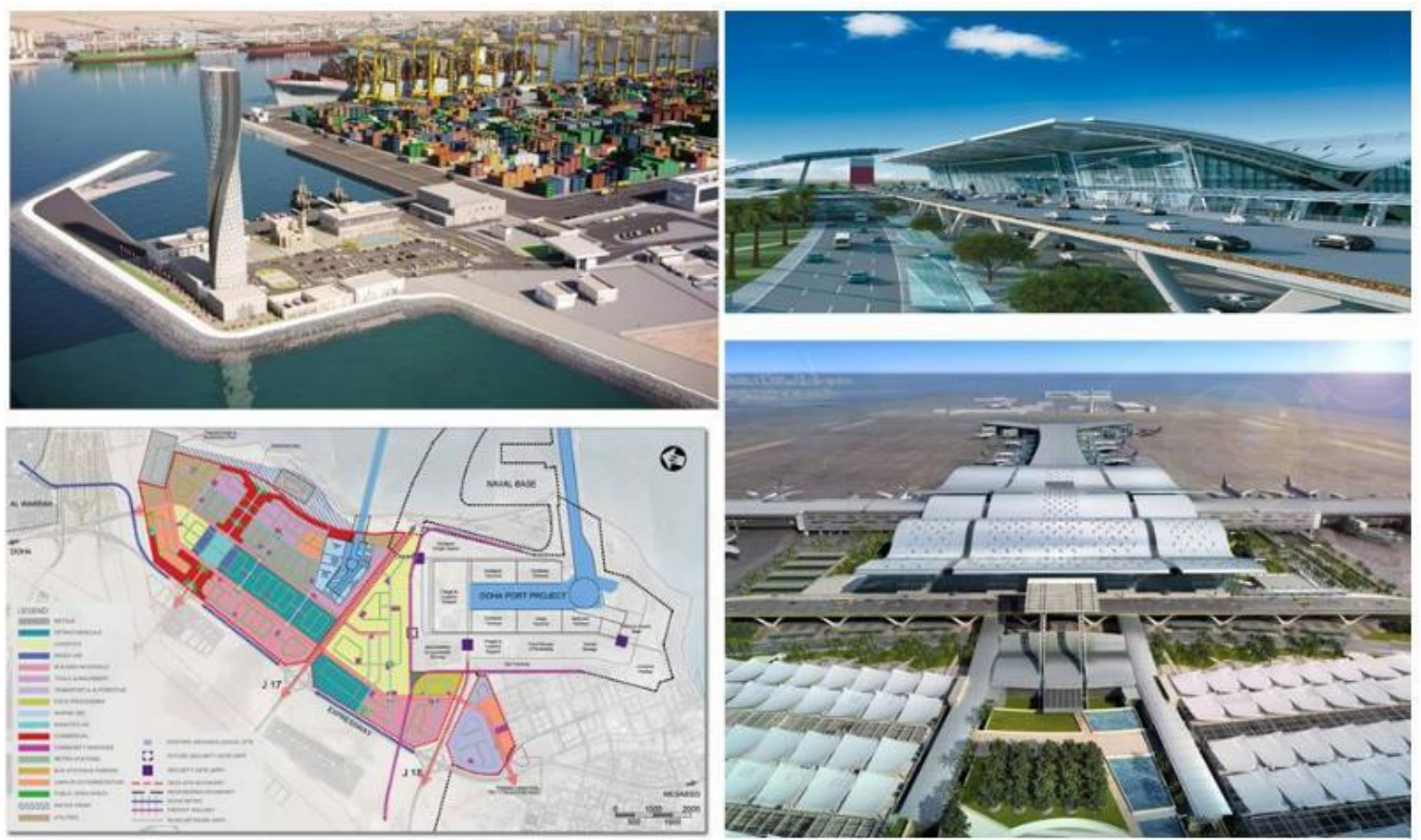

Figure 16 The unique airport, the state of the art Hmad port and the adjacent economic zones developed around the port facilitated the move of the city towards building new trade connections to overcome the impact of the blockade (Source: Courtesy of Ministry of Municipality).

\section{Conclusion}

The Model of Doha, Qatar extends the conceptualization of resilience to go beyond the wellknown risks and move to planning the city to face different forms of crisis. More significantly, prepare the city to face uncertainty as the case with oil prices fluctuation and its impact on the economic stability of the country. Such a model matches with Coaffee and Lee (2017) calls for a focus towards an integrated and adaptable model for coping with risk, crisis and uncertainty. In such time of uncertainty, urban planners are increasingly tasked with the responsibility of safeguarding the future of urbanized centers and those that live in them. In facing an unprecedented blockade from the closest allies and adjacent neighbors, getting ready for hosting the biggest sports event on earth; FIFA world cup and coping with radical changes in its economic base as a rentier capital, Doha provided a worth analysis and appreciation case. Observing Qatar after more than a year of blockade and compare its status in relation to the situation in the blockading countries would assert that Qatar provided a model to other small states on the resilience level (Abdelmoula and Taguia, 2018). The experience of Doha after the blockade asserts that an urban rational and holistic development mechanism could help improve the urban capability more effectively to cope with the various crises involved. The model of Doha illustrates the difference between process-oriented resilience than an outcome-oriented. Hence, Doha provides a rational urban development model because it is both resilient and sustainable. Part of the city' success story stems from the fact that social cohesion was considered as a pillar in enhancing the resilience capabilities of the city. It describes and illustrates the ideas, tools, and tactics being used to help engaged citizens, civic leaders, and urban professionals to work together to build viable urban society. The provided analysis illustrates that the Qatari model in delivering flexible and resilient cities capable of handling variables, risks and harsh changes without losing the rhythm of its growth and its insistence on preserving the status which was obtained on regional and 
global levels in the last decade, especially in the areas of integrated development and holistic modernization.

In contrast to most literature that views a small state's natural position in the global system should be that of weakness, attachment and ineffectiveness, Qatar has provided a model to the world that defies this prominent belief. Qatar's intelligent employment of its economic power, active diplomacy, coherent internal front, and relations and alliances has contributed to maintaining its stability, challenging the blockade, and defusing its impacts on all levels. Indeed, the case study of Qatar provides an interesting model for resilient cities because of the commitment to a set of strategies that brought about a qualitative difference in how to deal with various challenges, risks and unforeseen threats. Qatar' strategy as a model for resilient cities emerged from a number of fundamental pillars:

Weathering the storm by perceiving it as an opportunity is evident in the Qatari narrative. Despite facing these significant challenges, the broader Qatari economy has continued to grow. GDP expanded by $1.6 \%$ in 2017 and $2.2 \%$ last year, according to the IMF, with the economy forecast to expand by $2.6 \%$ in 2019 , well above the $0.3 \%$ average predicted for the Middle East. "Qatar's economy has successfully absorbed the shocks from the 2014-16 drop in hydrocarbon[s] prices and the 2017 diplomatic rift," as declared by the International Monetary Fund (IMF). Increased natural gas production, major infrastructure investment and the use of significant financial reserves from the country's sovereign wealth fund have all been highlighted as contributing factors to the stabilization of the economy. Depending on the mounting knowledge economy as an alternative economic base and set up the needed infrastructure for education, scientific research, culture and knowledge production which makes the transition from a resource to knowledge economy smoother. Intensifying the idea of a balanced social inclusion between major population sectors; the local citizens and working expatriates to create a sense of belonging, appreciation and recognition of mutual value and distinct roles of the country's rich human mosaic. Adopting the principles of sustainability and environmental compatibility as the main pillars of development for Qatar National Master Plan (QNMP). ONMP is based on a set of sustainable urban development values like transit-oriented development (TOD), sustainable urbanization, social balance and the preservation of the historical and cultural identity. And finally, dealing schematically and planner with major cities especially Doha as a framework for knowledge-based urban development through a network of research centers, universities, museums and the knowledge forums and make it available to all sectors of society in a way which would stimulate citizen and resident alike in a balanced manner.

\section{References}

Abdelmoula, Ezzeddine and Taguia, Haoues. (2018). Qatar's Resilience: A Model of Resisting Blockade and the Power of Small States. Doha: Al Jazeera Center for Studies.

Abdelmoula, Ezzeddine and Taguia, Haoues. (2017). The Blockade of Qatar: The Contexts and Repercussions of the Gulf Crisis. Doha: Al Jazeera Center for Studies.

Al Buainain, F 1999, Urbanisation in Qatar: A Study of the Residential and Commercial Land Development in Doha City, 1970 -1997, PhD Thesis, University of Salford, Salford.

Alraouf, Ali A. 2018. Knowledge-Based Urban Development in the Middle East. New York: IGI Global Publishing.

Alraouf, Ali. 2017. Interrogating Qatar's Urbanity as a Catalyst for Building Knowledge-Based Societies and Economies. In Bertelsen, Rasmus Gjedss; Noori, Neema; Rickli, Jean-Marc (eds.) Strategies of Knowledge Transfer For Economic Diversification In The Arab States Of The Gulf. Pp: 53 -66. London: Gerlach Press.

Alraouf, Ali. 2016A. "Dohaization": An Emerging Interface between Knowledge, Creativity, and Gulf Urbanity. Pp.: 47-68. In Katodrytis, George and Syed, Sharmeen. Gulf Cities as Interfaces. Cambridge: Gulf Research Centre Cambridge.

Alraouf, Ali. 2016B. Museums as a Catalyst for a New Urban and Cultural Identity in Qatar Interrogating the Case of Museum of Islamic Art. In Museums in Arabia: Transnational Practices and Regional Processes.) . Exell, Karen and Wakefield, Sarina (eds.) (Ashgate: UK, 2016). 
Alraouf, A. 2016. One Nation, One Myth and Two Museums Heritage, Architecture and Culture as Tools for Assembling Identity in Qatar. Representing the Nation: Heritage, Museums, National Narratives, and Identity in the Arab Gulf States, Publisher: Routledge, Editors: Pamela Erskine-Loftus, pp.79- 94.

Alraouf, A. 2015. Towards a holistic approach to sustainability: Heritage, architecture and culture as tools for assembling identity in Qatar. DOI: 10.5339/qproc.2015.qgbc.30.

Alraouf, Ali. 2012. A Tale of Two Souqs. In or Out of Place: The Paradox of Gulf Urban Diversity. Open House International Journal. Volume 37, Issue No. 2, June 2012. Pp:72-81.

Alraouf, Ali. 2008. Emerging Middle Eastern knowledge cities: the unfolding story. In Yigitcaular, T., and Koray,V., eds. Knowledge Based Urban Development: Planning and Application in the Information Era. IGI Global Publishing.

Baldwin, Cathy and King, Robin (2018). Social Sustainability, Climate Resilience and Community-Based Urban Development: What About the People? London and New York: Routledge.

Campbell, Kelvin. 2018. Making Massive Small Change. Building the Urban Society we want. London: Chelsea Green Publishing.

Coaffee, Jon and Lee, Peter. (2017). Urban Resilience: Planning for Risk, Crisis and Uncertainty. Palgrave Macmillan.

Cooke, Philip and Lazzeretti, Luciana (Eds.). 2018. The Role of Art and Culture for Regional and Urban Resilience 1st Edition. London and NY: Routledge.

Fromherz, A., 2012. Qatar: a Modern History. Washington, D.C.: Georgetown University Press.

Fromherz, Allen. 2013. Qatar: Rise to Power and Influence. London: I.B.Tauris.

Gray, Matthew. 2013. Qatar: Politics and the Challenges of Development. Boulder, CO: Lynne Rienner Publishers.

Jacobs, J. 1961. The Death and Life of Great American Cities. New York: Random House.

Jha, Abhas K.; Miner, Todd W. and Stanton-Geddes, Zuzana (eds.). (2013). Building Urban Resilience: Principles, Tools, and Practice. Washington D.D.: World Bank Publications.

Kamrava, Mehran. 2013. Qatar: Small State, Big Politics. New York: Cornell University Press.

Leichenko, Robin. (2011). Climate change and urban resilience. In Current Opinion in Environmental Sustainability. Volume 3, Issue 3, May 2011, Pages 164-168.

Meerow, Sara, Newell, Joshua P and Stults, Melissa. 2016. Defining urban resilience: A review. Landscape and Urban Planning. Volume 147, March 2016, Pages 38-49.

Nadine S. 2014. "Off and Running: Qatar Brands for FIFA World Cup, and LifeBeyond." In Under Construction: Logics of Urbanism in the Gulf Region, edited byWippel S, Bromber K, Steiner C and Krawietz B. Surrey UK: Ashgate, pp. 71-87.

Pizzo, Barbara. (2015). Problematizing resilience: Implications for planning theory and practice. Cities, Volume 43, March 2015, Pages 133-140.

Qatar National Development Framework (QNDF). 2016. The Ministry of Municipality and Environment.

QSDP. (2011) (Qatar General Secretariat of Development Planning) National Development Strategy 20112016. Gulf Publishing and Printing Company, Doha, Qatar.

Qatar Statistics Authority. (2015). QSA Population. Retrieved February 22, 2015, from http://www.qsa.gov.qa/eng/populationstructure.htm

Richer, R. A. Sustainable development in Qatar: Challenges and opportunities, QScience Connect 2014:22 http://dx.doi.org/10.5339/connect.2014.22.

Roberts, David B. 2017. Securing the Qatari State. Washington, DC: The Arab Gulf States Institute in Washington (AGSIW).

Roberts, David B. 2015. Qatar: Securing the Global Ambitions of a City-state. London: C Hurst \& Co Publishers Ltd.

Spaans, M.and Waterhout, B. (2017). Building up resilience in cities worldwide - Rotterdam as participant in the 100 resilient cities programme. Cities, 61 (2017), pp. 109-116.

The Oxford Business Group: Qatar Business Barometer. 2019 Edition.

Timon, M. (2014). The rise of resilience: Linking resilience and sustainability in city planning. Urban ecology at The New School in New York City, New York (2014).

Yamagata, Yoshiki and Maruyama, Hiroshi (Eds.). (2016). Urban Resilience: A Transformative Approach. London: Springer.

Zhang, Xiaoling and Li, Huan. (2018). Urban resilience and urban sustainability: What we know and what do not know? In Cities Volume 72, Part A, February 2018, Pages 141-148. 


\section{Resume}

Prof. Alraouf is an architect and urban designer with 35 years of academic, research and consultancy experience around the Middle East, and the world. He is interested in research and practice related to architectural, urban and sustainable people-based design and architecture. He was a Visiting Scholar at University of California at Berkeley-USA. Alraouf's research interests are post-carbon architecture and urbanism in the Gulf, inclusivity and diversity in contemporary cities, knowledge and creative cities, democratic public spaces and just cities, museums' architecture and Doha's architectural and urban model. He published more than 130 journal refereed papers, critical reviews, essays, in addition to books and book chapters. He serves in editorial boards and acts as a reviewer for international journals and conferences. He has been invited to present his research work at international institutions in over 30 countries such as UC Berkeley, University of Cambridge, Drury University, University of Oregon, International University in Malaysia, American University of Beirut, and American University in Sharjah. He is the recipient of number of awards including Modern Science and Arts University (MSA) Teaching Excellence Award 2004, Best Research Paper in Sharjah International Conference for Urban Planning 2008, Research Publication Achievement Award from University of Bahrain 2009, 2012 Excel campaign at Qatar University, Best Research Paper in IASTE Conference 2018 and Best Book Award by ISOCARP in 2018. Alraouf currently acts as head of research and development at Qatar Urban Planning Dept., a Board member in the international society of city planners and leader of Green Urbanism and Planning Group at Qatar Green Building Council. 